\title{
A PROIBIÇÃO DA PUBLICIDADE DE TABACO NA CONSTITUIÇÃ̃ MATERIAL BRASILEIRA: REFLEXÕES A PARTIR DA CONVENÇÃOO QUADRO DE CONTROLE DO TABACO
}

SUMÁRIO: Introdução; 1.1 A defesa do consumidor como direito fundamental; 2 A defesa do consumidor em relação à publicidade de produtos nocivos e perigosos à saúde bumana; 3 A proibição constitucional da publicidade do tabaco à luz da Convenção Quadro de Controle do Tabaco; 4 Considerações finais; Referências.

RESUMO: O tabagismo é a principal causa evitável de morte no mundo, de modo que se deve adotar medidas efetivas para o controle de tabaco, dentre as quais a proibição de propaganda, promoção e patrocínio pelas empresas de tabaco. Para responder a esta epidemia, a Lei n. ${ }^{\circ} 9.294$, de 15 de julho de 1996, proíbe a propaganda comercial de tabaco, cuja constitucionalidade fora questionada no Supremo Tribunal Federal, sob alegação de violação do princípio da proporcionalidade. Nesse toar, o presente trabalho científico tem como objetivo principal apresentar, a partir de uma pesquisa doutrinária e legislativa, argumentos favoráveis no sentido de que a publicidade do tabaco está vedada pela própria Constituição Federal e que, por consequência, não há qualquer vício de inconstitucionalidade na proibição legal da propaganda do tabaco.

PALAVRAS-CHAVE: Defesa do consumidor; Publicidade de tabaco; Convenção Quadro de Controle do Tabaco; Constituição material.

\section{PROHIBITION OF SMOKING ADVERTISEMENTS IN THE BRAZILIAN CONSTITUTION: DISCUSSION ON THE CONVENTION SMOKING CONTROL FRAMEWORK}

ABSTRACT: Since smoking is the main avoidable mortality cause worldwide, effective measures should be undertaken for the control of smoking, especially advertisements, sales and funding by tobacco companies. In fact, Law n. 9294 of July 15, 1996 prohibits commercial propaganda of cigarettes but its constitutionality was questioned by the Brazilian Higher Court under the theme of violation of the principle of proportionality. Current analysis presents a doctrine and legislation research on favorable arguments to show that the very Constitution prohibits

Doutorando no Programa de Pós-Graduação em Direito pela Pontifícia Universidade Católica do Rio Grande do Sul (PUCRS); Docente de Direito Constitucional da FANESE; Promotor de Justiça em Sergipe, Brasil. E-mail: aclresende@bol.com.br 
smoking advertisements. Consequently, there are no unconstitutional factors in the legal prohibition of tobacco propaganda.

KEY WORDS: Consumer defense; Smoking advertisements; Convention Tobacco Control Frame; Constitution.

\section{LA PROHIBICIÓN DE LA PUBLICIDAD DEL TABACO EN LA CONSTITUCIÓN BRASILEÑA: REFLEXIONES A PARTIR DE LA CONVENCIÓN DEL CUADRO DE CONTROL DEL TABACO}

RESUMEN: El tabaquismo es la principal causa evitable de muerte en el mundo, de tal manera que se deben adoptar medidas efectivas para el control del tabaco, entre ellas la prohibición de la propaganda, promoción y patrocinio de las empresas de tabaco. Para contestar a esta epidemia, la Ley $\mathrm{n}^{0}$ 9294, de 15 de julio de 1996, prohíbe la propaganda comercial del tabaco, cuya constitucionalidad fue cuestionada en el Supremo Tribunal Federal, bajo la alegación de violación del principio de proporcionalidad. En ese contexto, este trabajo científico tiene como objetivo principal presentar, a partir de una pesquisa doctrinaria y legislativa, argumentos favorables a la demostración de que la publicidad del tabaco está vedada por la propia Constitución Federal y que, por consecuencia, no hay cualquier vicio de inconstitucionalidad en la prohibición legal de la propaganda del tabaco.

PALABRAS-CLAVE: Defensa del consumidor; Publicidad del tabaco; Convención del Cuadro de Control del tabaco, Constitución material.

\section{INTRODUÇÃO}

A Organização Mundial da Saúde (OMS) considera o tabagismo a principal causa de morte evitável no mundo. De acordo com a organização aproximadamente dois bilhões de pessoas são fumantes, dos quais mais de oitenta por cento vivem em países subdesenvolvidos ou em desenvolvimento ${ }^{02}$.

As doenças relacionadas com o tabagismo têm elevados custos para os cofres públicos porque acarretam despesas com assistência médica aos fumantes

${ }^{22}$ ORGANIZAÇÃO MUNDIAL DA SAÚDE. Who report on the global tabacco epidemic: raising taxes on tabacco, 2015, p. 09. Disponível em: <http://apps.who.int/iris/bitstream/10665/178574/1/9789240694606_eng.pd$\mathrm{f}$ ?ua $=1 \& u a=1>$. Acesso em 31 de maio de 2016. 
enfermos e com benefícios previdenciários ${ }^{03}$, recursos esses que deixam de ser aplicados na efetivação de outros direitos igualmente importantes para os indivíduos e a sociedade.

Com o objetivo de controlar o consumo do tabaco, a Lei Federal n..$^{\circ}$ 9.294, de 15 de julho de 1996, proíbe, em seu art. $3^{\circ}$, a propaganda comercial de cigarros, cigarrilhas, charutos, cachimbos ou qualquer outro produto fumígeno, derivado ou não do tabaco.

Insatisfeita com a proibição legal, a Confederação Nacional da Indústria propôs ação direta de inconstitucionalidade, perante o Supremo Tribunal Federal, visando, dentre outros pedidos, a declaração de inconstitucionalidade da proibição à publicidade do tabaco, sob alegação, em suma, de violação do princípio da proporcionalidade.

Nesse contexto, o presente artigo científico tem por finalidade demonstrar, a partir do diálogo entre a ordem jurídica brasileira e o ordenamento jurídico internacional de proteção dos direitos humanos, que a publicidade do tabaco está vedada pela própria Constituição Federal e que, por consequência, não há qualquer vício de inconstitucionalidade no art. $3^{\circ}$ da Lei Federal n. 9.294, de 15 de julho de 1996.

Primeiramente, discutir-se-á a inclusão da defesa do consumidor no rol dos direitos fundamentais consagrados na Carta Magna. Em seguida, tratar-se-á da necessidade da proibição da publicidade do tabaco em prol do direito à vida com dignidade e à saúde humana.

Após, analisar-se-á o diálogo entre o direito constitucional brasileiro e o direito internacional dos direitos humanos e, por fim, refletir-se-á sobre a natureza e os efeitos jurídicos da Convenção Quadro para o Controle do Tabaco na ordem jurídica nacional.

\subsection{A DEFESA DO CONSUMIDOR COMO DIREITO FUNDAMENTAL}

A Constituição Federal reservou inteiramente o Título II aos Direitos e Garantias Fundamentais, nele positivando um leque amplo e extenso de direitos fundamentais do ser humano, classificando-os em cinco espécies, a saber: a) direitos e deveres individuais; b) direitos e deveres coletivos; c) direitos sociais; d) direitos à nacionalidade e e) direitos políticos.

${ }^{03}$ ORGANIZAÇÃO MUNDIAL DA SAÚDE. Who report on the global tabacco epidemic: raising taxes on tabacco... Op. Cit., p. 09. 
No entanto, o rol do referido Título II da Carta Magna não é taxativo, mas meramente exemplificativo porque o art. $5^{\circ}, \S 2^{\circ}$, da própria Constituição Federal ressalva que "os direitos e garantias expressos nesta Constituição não excluem outros decorrentes do regime e dos princípios por ela adotados, ou dos tratados internacionais em que a República Federativa do Brasil seja parte".

Os direitos fundamentais não são apenas aqueles consagrados $\mathrm{e}$ reconhecidos formalmente na Constituição, pois, como acima referido, a Carta Magna admite a existência de outros direitos fundamentais não inseridos no rol do Título II, reconhecendo, destarte, a existência dos chamados direitos materialmente fundamentais.

Os direitos fundamentais podem ser classificados em: direitos formalmente fundamentais e direitos materialmente fundamentais. Serão formalmente fundamentais, os direitos expressamente incorporados no catálogo dos direitos fundamentais da Constituição, independentemente de seu conteúdo ${ }^{04}$.

Por sua vez, os direitos materialmente fundamentais poderão ser identificados a partir do conceito aberto de direitos fundamentais adotado pelo art. $5^{\circ}, \S 2^{\circ}$, da Constituição Federal, pois possibilita o reconhecimento de direitos fundamentais positivados em outras partes do texto constitucional ou em tratados internacionais e até mesmo na identificação de direitos fundamentais não-escritos ou implícitos na Constituição, que sejam decorrentes do regime e princípios por ela adotados ${ }^{05}$.

A identificação e a caracterização de um direito materialmente dotado de fundamentalidade não são tarefas fáceis para o intérprete e aplicador do direito, pois não decorrem apenas da simples leitura do texto constitucional, na medida em que poderão, como visto alhures, existir outros direitos fundamentais dispersos no corpo da Constituição, positivados em tratados internacionais ou consagrados em princípios não assentados na Carta Magna.

A definição de direito fundamental, proposta por Ingo Wolfgang Sarlet, permite ao intérprete a identificação e, consequentemente, a efetivação e a proteção de direitos fundamentais exclusivamente materiais, isto é, não consagrados expressamente no catálogo do Título II da Constituição Federal. A propósito:

\footnotetext{
${ }^{04}$ ALEXY, Robert. Teoria dos direitos fundamentais. Tradução de Virgílio Afonso da Silva. São Paulo: Malheiros, 2008 , p. 68.

${ }^{05}$ SARLET, Ingo Wolfgang. A eficácia dos direitos fundamentais: uma teoria geral dos direitos fundamentais na perspectiva constitucional. 12. ed.. Porto Alegre: Livraria do Advogado, 2015, p. 72.
} 
Direitos fundamentais são, portanto, todas aquelas posições jurídicas concernentes às pessoas, que, do ponto de vista do direito constitucional positivo, foram, por seu conteúdo e importância (fundamentalidade em sentido material), integradas ao texto da Constituição e, portanto, retiradas da esfera de disponibilidade dos poderes constituídos (fundamentalidade formal), bem como as que, por seu conteúdo e significado, possam lhes ser equiparados, agregando-se à Constituição material, tendo, ou não, assento na Constituição formal (aqui considerada a abertura material do Catálogo) ${ }^{06}$.

Assim, reconhecem-se direitos que, apesar de não positivados formalmente no rol do Título II da Constituição Federal, por seu conteúdo, importância e significado, podem ser considerados fundamentais e, por isso mesmo, inseridos na Carta Constitucional, produzindo todos os efeitos jurídicos como se direitos formalmente fundamentais fossem.

A dignidade da pessoa humana não é, ela mesma, um direito fundamental ${ }^{07}$, mas, enquanto princípio fundamental do Estado brasileiro, é a fonte e o fundamento dos direitos fundamentais e dos direitos humanos ${ }^{08}$, atuando, portanto, como critério de identificação de direitos materialmente fundamentais eventualmente existentes na ordem jurídica do Brasil.

E nesse contexto, é possível afirmar que a defesa do consumidor é direito material e formalmente fundamental positivado na ordem jurídica brasileira.

A defesa do consumidor é direito formalmente fundamental porque está expressamente positivada no art. $5^{\circ}$, inciso XXXII, da Constituição Federal. Ademais, por estar diretamente vinculada à dignidade humana, é também um direito materialmente fundamental ${ }^{09}$.

A identificação da defesa do consumidor como direito fundamental decorre do reconhecimento jurídico de uma necessidade essencial humana que é a imprescindibilidade do consumo na sociedade de consumo ${ }^{10}$ e o cidadão brasileiro, enquanto ser humano e quando estiver na qualidade de consumidor, deve ter a sua dignidade promovida e protegida pelo Estado ${ }^{11}$.

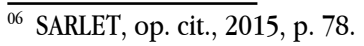

${ }^{07}$ SARLET, Ingo Wolfgang. Dignidade da pessoa humana e direitos fundamentais na Constituição Federal de 1988. 9. ed.. Porto Alegre: Livraria do Advogado, 2012, p. 84.

${ }^{08}$ Ibidem, 2012, p. 95.

${ }^{09}$ PASQUALOTTO, Adalberto. Fundamentalidade e efetividade da defesa do consumidor. Direitos Fundamentais \& Justiça, vol. 9, p. 66-100, out./dez 2009, p. 76.

${ }^{10}$ MIRAGEM, Bruno Nubens Barbosa. O direito do consumidor como direito fundamental: consequências jurídicas de um conceito. Revista de Direito do Consumidor. Vol. 43, p. 111-132, jul./set. 2002, p.114.

${ }^{11}$ EFING, Antônio Carlos. Fundamentos do direito das relações de consumo. 3. ed.. Curitiba: Juruá, 2011, p. 33.
} 
A Constituição Federal de 1988 colocou a pessoa do consumidor no centro das atenções do sistema jurídico, deixando em segundo plano os aspectos meramente patrimoniais, uma vez que o direito do consumidor "lida com o essencial da vida humana, conecta-se com os princípios da dignidade da pessoa e a garantia do mínimo existencial"12 e, desse modo, não se pode negar a fundamentalidade material da defesa do consumidor ${ }^{13}$.

A qualificação de um direito fundamental em princípio jurídico é possível porque não se trata de conceitos antitéticos e reciprocamente excludentes, na medida em que as normas constitucionais definidoras de direitos fundamentais são eminentemente principiológicas ${ }^{14}$.

Nessa linha de raciocínio, a defesa do consumidor é direito fundamental e princípio constitucional expresso no art. 170, inciso V, da Constituição da República, de aplicabilidade direta e imediata, que impõe ao Estado a implementação de medidas fáticas e jurídicas de caráter interventivo voltadas à proteção do consumidor ${ }^{15} \mathrm{e}$ limites à livre iniciativa e à autonomia da vontade ${ }^{16}$.

\section{A DEFESA DO CONSUMIDOR EM RELAÇÃO À PUBLICIDADE DE PRODUTOS NOCIVOS E PERIGOSOS À SAÚDE HUMANA}

A sociedade de consumo se caracteriza como um grupo social em estágio avançado de desenvolvimento industrial, com grande circulação e consumo de bens e serviços oferecidos graças a uma produção intensiva, pois o homem contemporâneo tem uma necessidade ilimitada de adquirir e usar inúmeros bens e serviços ${ }^{17}$.

Os produtos não são fabricados em função do seu respectivo valor de uso ou da sua utilidade, mas antes em função de seu perecimento calculado, da sua

\footnotetext{
$\overline{12}$ PASQUALOTTO, Adalberto. Fundamentalidade e efetividade da defesa do consumidor. Direitos Fundamentais \& Justiça... Op. Cit., p. 70.

${ }^{13}$ Ibidem, 2009, p. 77.

${ }^{14}$ SARLET, op. cit., 2012, p. 83.

${ }^{15}$ GRAU, Eros Roberto. A ordem econômica na Constituição de 1988. 15. Ed.. São Paulo: Malheiros, 2012, p. 250.

${ }^{16}$ MIRAGEM, Bruno; MARQUES, Cláudia Lima. A constitucionalidade das restrições à publicidade do tabaco por lei federal: diálogo e adequação do princípio da livre iniciativa econômica à defesa do consumidor e da saúde pública. In: PASQUALOTTO, Adalberto (Org.). Publicidade de tabaco: frente e verso da liberdade de expressão. São Paulo: Atlas, p. 03-37, 2015, p. 20.

${ }^{17}$ FAJARDO, Elias. Consumo consciente, comércio justo: conhecimento e cidadania como fatores econômicos. Rio de Janeiro: Senac Nacional, 2010, p. 14.
} 
morte ${ }^{18}$, ou seja, os bens e serviços inseridos no mercado de consumo têm vida curta e sua morte é programada. É a chamada "obsolescência programada".

As empresas diminuem o ciclo de vida dos produtos, objetivando a sua substituição por novos bens e serviços, aumentando assim os lucros através das vendas constantes e maiores de seus produtos. Enfim, "os mercados de consumo se concentram na desvalorização imediata de suas antigas ofertas, a fim de limpar a área da demanda pública para que novas ofertas a preencham" ${ }^{19}$, por meio da inserção de novos bens e serviços no mercado.

A publicidade é instrumento indispensável ao exercício da atividade econômica pelas empresas, uma vez que é por meio das mensagens publicitárias que os agentes econômicos divulgam seus produtos lançados no mercado ${ }^{20}$. A publicidade comercial é veiculada de diversas formas pelas empresas com a finalidade precípua de vender ou promover seus bens ou serviços e, com isso, influir nas decisões de consumo das pessoas ${ }^{21}$, aumentando seus lucros. A publicidade tem, portanto, função indutora de comportamentos de consumo.

Já em 1964, Herbert Marcuse alertava que a sociedade à época era totalitária, no sentido de que a tecnologia e a economia manipulavam as necessidades humanas por interesses escusos ${ }^{22}$. Tal pensamento ainda é atual, pois a sociedade pós-moderna utiliza de técnicas de persuasão, através da publicidade de massa, para manipular os desejos e as carências humanas em prol do mercado e do lucro, induzindo-os a ter necessidades virtuais para cada vez mais adquirir bens e serviços que não incentivam a felicidade humana e o desenvolvimento da personalidade ${ }^{23}$.

A publicidade comercial afeta negativa e decisivamente a liberdade das pessoas no que toca à autonomia de escolha na aquisição de bens e serviços porque as empresas produzem carências e desejos nas pessoas, que passam a ser julgadas por aquilo que consomem, vestem ou calçam, pelos locais que frequentam, pelos bens materiais que possuem e mostram aos outros membros da sociedade.

Os indivíduos são incentivados pela publicidade comercial a consumir

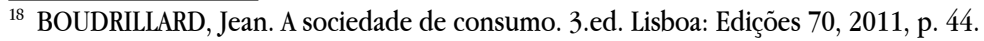

${ }^{19}$ BAUMAN, Zygmunt. Vida para o consumo: a transformação das pessoas em mercadoria. Rio de Janeiro: Zahar, 2008, p. 128.

${ }^{20}$ DIAS, Lúcia Ancona Lopez de Magalhães. Publicidade e hipervulneráveis: limitar, proibir ou regular? Revista de Direito do Consumidor, vol. 99, p. 285-305, mai.jun. 2015, p. 287.

${ }^{21}$ PASQUALOTTO, Adalberto. Direito e publicidade em ritmo de descompasso. Revista de Direito do Consumidor, vol. 100, p. 501-527, jul./ago. 2015, p. 503-504.

${ }^{22}$ MARCUSE, Herbert. O homem unidimensional: estudos da ideologia da sociedade industrial avançada. São Paulo: EDIPRO, 2015, p. 42.

${ }^{23}$ MARCUSE, op. cit., 2015, p. 49-50.
} 
cada vez mais, a adquirir produtos não essenciais e desnecessários. As mensagens mercadológicas de massa são usadas para aumentar os lucros das empresas, pois a "publicidade realiza o prodígio de um orçamento considerável gasto com o único fim, não de acrescentar, mas de tirar o valor de uso dos objectos, de diminuir o seu valor/tempo, sujeitando-se ao valor/moda e à renovação acelerada"24, já que incute na mente das pessoas que os seus produtos se tornaram defasados, induzindo-as, assim, a adquirir novos produtos.

A sobrevivência da sociedade de consumo depende da criação de falsas necessidades por novas mercadorias. É preciso, pois, embutir na consciência dos homens a necessidade de adquirir novos bens e serviços, a fim de que o produto, ao ser inserido no mercado, seja ao máximo consumido e, em seguida, substituído por outra mercadoria ${ }^{25}$.

Zygmunt Bauman afirma que "o consumo é uma condição, e um aspecto, permanente e irremovível, sem limites temporais ou históricos; um elemento inseparável da sobrevivência biológica que nós humanos compartilhamos com todos os outros organismos vivos" ${ }^{26}$, ou seja, é uma necessidade vital do ser humano. Consumimos para viver.

Por outro lado, o consumismo, conceituado como a "expansão de um conjunto de valores hedonistas que estimula o indivíduo, ou a sociedade, a buscar satisfação e felicidade através da aquisição e exibição pública de uma grande quantidade de bens e serviços" ${ }^{27}$, é um dos principais problemas da sociedade moderna.

Hoje, os indivíduos passam a consumir com os olhos e emoções voltados apenas para eles mesmos, num ato extremamente individualista e egoísta, sem se preocupar com as consequências socioambientais de suas decisões de consumo. Vive-se uma cultura de consumismo.

É mister, portanto, proteger o consumidor da publicidade, não somente a enganosa ou a abusiva, mas a relativa a produtos nocivos ou perigosos à vida e à saúde humana, dentre os quais o tabaco, notadamente porque as empresas praticam o que Ulrich Beck chama de "irresponsabilidade organizada", na medida em que, cientes da existência dos riscos decorrentes de suas atividades industriais e comerciais para

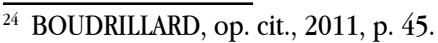

${ }^{25}$ PORTILHO, Fátima. Sustentabilidade ambiental, consumo e cidadania. 2.ed. São Paulo: Cortez, 2010, p. 21-22.

${ }^{26}$ BAUMAN, op. cit., 2008, p. 37.

${ }^{27}$ PORTILHO, op. cit, 2010, p. 25.
} 
o ser humano e para a natureza, ocultam-nos ou dissimulam-nos de acordo com os seus interesses políticos e econômicos, transmitindo para a sociedade a sensação de risco inexistente ou controlado ${ }^{28}$.

A indústria do tabaco se utiliza de táticas de publicidade com o propósito de angariar novos consumidores de tabaco, aumentar o consumo do fumo, fragilizar as campanhas de saúde pública e incentivar ex-fumantes a voltar ao vício ${ }^{29}$. As mensagens publicitárias normalmente apresentam o consumo do tabaco como uma prática habitual e elegante, utilizando-se, na maioria das vezes, de informações falsas ou enganosas ${ }^{30}$.

Nesse contexto, o legislador constituinte previu a possibilidade de restrições, por meio de lei federal, a propaganda comercial de produtos nocivos ao ser humano, inclusive o tabaco. A propósito:

Art. 220. A manifestação do pensamento, a criação, a expressão e a informação, sob qualquer forma, processo ou veículo não sofrerão qualquer restrição, observado o disposto nesta Constituição.

$[\ldots]$

$\S 3^{\circ}$ Compete à lei federal:

$[\ldots]$

II - estabelecer os meios legais que garantam à pessoa e à família a possibilidade de se defenderem de programas ou programações de rádio e televisão que contrariem o disposto no art. 221, bem como da propaganda de produtos, práticas e serviços que possam ser nocivos à saúde e ao meio ambiente.

$\S 4^{\circ}$ A propaganda comercial de tabaco, bebidas alcoólicas, agrotóxicos, medicamentos e terapias estará sujeita a restrições legais, nos termos do inciso II do parágrafo anterior, e conterá, sempre que necessário, advertência sobre os malefícios decorrentes de seu uso.

O legislador ordinário cumpriu, por sua vez, o comando constitucional acima mencionado com a edição da Lei Federal n. ${ }^{\circ}$ 9.294, de 15 de julho de 1996, aduzindo, em seu art. $3^{\circ}$, com a redação dada pela Lei n. ${ }^{\circ} 12.546$, de 14 de dezembro de 2011, que "é vedada, em todo o território nacional, a propaganda comercial de cigarros, cigarrilhas, charutos, cachimbos ou qualquer outro produto fumígeno, derivado ou não do tabaco".

\footnotetext{
${ }^{28}$ BECK, Ulrich. Ecological Politics in an Age of Risk. Londres: Polity Publications, 1995, p. 61.

${ }^{29}$ CABRERA, Oscar; GUILLEN, Paula Ávila; CARBALLO, Juan. Viabilidade jurídica de una proibição completa da publicidade de tabaco: o caso perante a Corte Constitucional da Colômbia. In: PASQUALOTTO, Adalberto (Org.). Publicidade de tabaco: frente e verso da liberdade de expressão comercial. São Paulo: Atlas, p. 253-275, 2015, p. 258.

${ }^{30}$ Idem.
} 
A proibição legal da publicidade do tabaco tem por escopo promover e proteger os direitos fundamentais à vida com dignidade e à saúde mediante $\mathrm{o}$ desestímulo do consumo de produtos derivados do fumo em razão dos comprovados malefícios do tabaco para a saúde humana ${ }^{31}$.

Não obstante a finalidade legislativa, a Confederação Nacional da Indústria propôs ação direta de inconstitucionalidade, perante o Supremo Tribunal Federal, visando, dentre outros pedidos, a declaração de inconstitucionalidade da proibição legal à publicidade do tabaco, por entender que tal medida restritiva acarreta o sacrifício dos núcleos essenciais do direito à publicidade, à livre iniciativa e à divulgação publicitária e viola o princípio da proporcionalidade.

Contudo, a solução da controvérsia constitucional posta na Ação Direta de Inconstitucionalidade tombada sob número 3.311 passa necessariamente pelo diálogo entre a ordem jurídica brasileira e o ordenamento jurídico internacional de proteção dos direitos humanos.

\section{A PROIBIÇÃo CONSTituCIONAL DA PUBLICIDADE DO TABACO À LUZ DA CONVENÇÃO QUADRO DE CONTROLE DO TABACO}

No Estado liberal do século XIX, a lei era a fonte hegemônica do Direito e passou a ser o instrumento utilizado para aplicar e interpretar a Constituição, limitar o poder estatal e manifestar a vontade popular ${ }^{32}$, de maneira que o pensamento jurídico vigente até primeira metade do século XX, o positivismo jurídico, fundava-se na ideia da observância "cega" da lei, afastando do Direito a filosofia, os princípios, os valores e o sentido de Justiça ${ }^{33}$.

Os valores morais vigentes numa comunidade política não podiam ser, segundo o positivismo jurídico, levados em consideração pelo direito e pela ciência jurídica, uma vez que o conceito de direito era definido de modo a não incluir elementos morais ${ }^{34}$. O direito deveria ser examinado e compreendido de modo

${ }^{31}$ DALLARI, Dalmo de Abreu. Controle do uso do tabaco: constitucionalidade do controle da distribuição e da publicidade. In: PASQUALOTTO, Adalberto (Org.). Publicidade de tabaco: frente e verso da liberdade de expressão comercial. São Paulo, Atlas, p. 38-45, 2015, p. 38.

${ }^{32}$ MÖLLER, Max. Teoria geral do neoconstitucionalismo: bases teóricas do constitucionalismo contemporâneo. Porto Alegre: Livraria do Advogado, 2011, p. 24.

${ }^{33}$ BARROSO, Luís Roberto. Curso de direito constitucional contemporâneo: os conceitos fundamentais e a construção do novo modelo. 4. ed.. São Paulo: Saraiva, 2013, p. 262.

${ }^{34}$ ALEXY, Robert. Conceito e validade do direito. São Paulo: WMF Martins Fontes, 2009, p. 3. 
distinto dos demais campos científicos.

Nesse cenário, tem-se a ascensão do fascismo ao poder, na Itália, e do nazismo, na Alemanha, que retiravam da "lei" o fundamento de validade das atrocidades praticadas contra negros, ciganos, homossexuais e, notadamente, judeus durante a Segunda Guerra Mundial.

As concepções da infalibilidade do legislador, da lei como fonte única do Direito e de um ordenamento jurídico indiferente a valores éticos promoveram o fracasso político do positivismo jurídico porque já não mais se aceitava, no pensamento jurídico do pós-guerra, tais ideias ${ }^{35}$.

Por essa razão, o constitucionalismo mundial sofreu grandes e profundas transformações, após a Segunda Guerra Mundial, com o surgimento do póspositivismo e do neoconstitucionalismo ${ }^{36}$, bem como a emergência dos sistemas internacionais de proteção dos direitos humanos.

A proteção internacional dos direitos humanos está estruturada em dois tipos de sistemas de proteção, quais sejam, o global e os regionais. O sistema global foi institucionalizado pela Organização das Nações Unidas (ONU), após a Segunda Guerra Mundial, cujos principais instrumentos normativos são a Declaração Universal dos Direitos Humanos de 1948, o Pacto Internacional dos Direitos Civis e Políticos e o Pacto Internacional dos Direitos Econômicos, Sociais e Culturais.

Os sistemas regionais de proteção dos direitos humanos foram estruturados por organizações continentais, em especial a Organização dos Estados Americanos, o Conselho da Europa e a União Africana, ao longo da segunda metade do século XX. Os três principais sistemas regionais de proteção dos direitos humanos são o interamericano, o europeu e o africano, apesar de haver, ainda que de forma incipiente, a formação de um sistema árabe-islâmico de proteção dos direitos humanos, todos com o propósito de promover a proteção e valorização dos direitos humanos na região.

Os sistemas global e regionais são verdadeiros instrumentos de proteção dos direitos humanos no plano internacional. Ambos são fundados no princípio da dignidade humana e, por isso, complementam-se e interagem com os sistemas nacionais de proteção dos direitos humanos, a fim de proporcionar a maior efetividade possível à promoção e proteção dos direitos humanos.

\footnotetext{
$\overline{35}$ BARROSO, op. cit., 2013, p. 264.

${ }^{36}$ Alguns autores se referem aos termos "constitucionalismo contemporâneo" ou "pós-positivismo" como sinônimos de "neoconstitucionalismo".
} 
Têm-se, portanto, o surgimento de ordens jurídicas internacionais e, com eles, a disseminação de documentos internacionais vocacionados à proteção dos direitos humanos, com força jurídica vinculante no âmbito do direito interno dos Estados.

A Constituição Federal estabeleceu, em seu artigo $5^{\circ}, \S 2^{\circ}$, cláusula de abertura do sistema jurídico brasileiro às ordens jurídicas internacionais, em matéria de direitos humanos, ao ressaltar que os direitos e garantias expressos na Carta Constitucional não excluem outros decorrentes do regime e dos princípios adotados por ela ou por tratados internacionais em que a República Federativa do Brasil seja parte.

A Lex Maxima possibilita, portanto, a inclusão no catálogo de direitos constitucionalmente protegidos os direitos humanos positivados expressa ou implicitamente em convenções internacionais em que o Brasil seja signatário.

Em essência, os "direitos fundamentais" e os "direitos humanos" visam resguardar a primazia da dignidade da pessoa humana e os seus conteúdos estão, sobretudo com a emergência do Direito Internacional dos Direitos Humanos, num processo crescente de aproximação e harmonização.

A Constituição da República atribui, ex vi do disposto em seu artigo $5^{\circ}$, $\S 2^{\circ}$, aos tratados internacionais de direitos humanos a natureza jurídica de norma constitucional ${ }^{37}$. As normas internacionais definidoras de direitos humanos são normas materialmente constitucionais e integram o chamado bloco de constitucionalidade ${ }^{38} \mathrm{e}$ tais direitos são constitucionalmente protegidos.

Com a inserção do $\S 3^{\circ}$ ao artigo $5^{\circ}$ da Constituição Federal, têm-se duas categorias de tratados internacionais de direitos humanos, quais sejam: a) os materialmente constitucionais; e b) os material e formalmente constitucionais. Todas as convenções internacionais de direitos humanos são materialmente constitucionais em razão do disposto no artigo $5^{\circ}, \S 2^{\circ}$ e poderão ter também a qualidade de formalmente constitucionais se aprovados segundo o rito especial estabelecido pelo $\operatorname{artigo} 5^{\circ}, \S 3^{\circ}$ da Constituição Federal ${ }^{39}$.

A Convenção Quadro de Controle do Tabaco tem a natureza jurídica especial de tratado internacional de direitos humanos, na medida em que se destina à proteção do indivíduo, diferenciando-se, por isso, dos tratados internacionais

${ }_{37}$ PIOVESAN, Flávia. Direitos humanos e o direito constitucional internacional. 14. ed., São Paulo: Saraiva, 2013, p. 114.

${ }^{38}$ Ibidem, 2013, p. 117.

39 Ibidem 2013, p. 134. 
tradicionais, que são celebrados em benefício recíproco dos Estados pactuantes ${ }^{40}$, e seus preceitos são vinculativos e obrigatórios por parte dos Estados signatários ${ }^{41}$.

$\mathrm{Na}$ qualidade de tratado internacional de direitos humanos, foi incorporada ao direito nacional como norma constitucional ${ }^{42}$ e integra a Constituição material brasileira. A propósito, José Joaquim Gomes Canotilho entende por Constituição material:

[...] o conjunto de fins e valores constitutivos do princípio efectivo da unidade e permanência de um ordenamento jurídico (dimensão objectiva), e o conjunto de forças políticas e sociais (dimensão subjectiva) que exprimem esses fins ou valores, assegurando a estes a respectiva prossecução e concretização, algumas vezes para além da própria constituição escrita. Ao contrário do que muitas vezes se pensa e vê escrito, a constituição material não se reconduz a um simples "poder de facto" ("relações de poder e influência", "facto político puro"), pois a constituição material tem também uma função ordenadora. A chamada força normativa de constituição (K. Hesse) pressupõe, a maior parte das vezes, a vontade de constituição, ou seja, a explicitação na constituição escrita ou formal do complexo de fins e valores agitados pelas constelações políticas e sociais a nível da constituição material ${ }^{43}$.

A Constituição material é composta pelas normas relativas à estrutura do Estado, à organização dos poderes e aos direitos e garantias fundamentais ${ }^{44} \mathrm{e}$ permite a abertura da Constituição a outros direitos fundamentais não elencados no Título II da Carta Magna e aos direitos humanos positivados em tratados internacionais.

Com efeito, a Constituição é um sistema aberto de regras e princípios ${ }^{45}$ que vai além da Constituição formal, fruto do poder constituinte, de modo a permitir a recepção de princípios não escritos no texto constitucional.

A Carta Magna de 1988 reconhece expressamente, em seu art. $5^{\circ}, \S 2^{\circ}$, a

\footnotetext{
${ }^{40}$ ALCALÁ, Humberto Nogueira. El diálogo interjurisdiccional y control de convencionalidad entre tribunales nacionales y Corte Interamericana de Derechos Humanos en Chile. In: SARLET, Ingo Wolfgang; GOMES, Eduardo Biacchi; STRAPAZZON, Carlos Luiz (Org.). Direitos humanos e fundamentais na América do Sul. Porto Alegre: Livraria do Advogado, 2015, p. 12.

${ }^{41}$ DONNELLY, Jack. Universal human rights in theory and practice. 3. ed., New York: Cornell University Press, 2013, p. 174-175.

${ }^{42}$ PASQUALOTTO, Adalberto. A Convenção Quadro para o controle do tabaco como reforço da constitucionalidade da proibição da publicidade do tabaco. Revista de Direito do Consumidor, vol. 91, p. 169-208, jan/fev. 2014, p. 173.

${ }^{43}$ CANOTILHO, José Joaquim Gomes. Direito constitucional e teoria da Constituição. 7. ed. Coimbra: Almedina, 2011, p. 1.139.

${ }^{44}$ SARLET, Ingo Wolfgang; MARINONI, Luiz Guilherme; MITIDIERO, Daniel. Curso de direito constitucional. 4. ed., São Paulo: Saraiva, 2015, p. 71.

${ }^{45}$ MIRANDA, Jorge. Teoria do Estado e da Constituição. Rio de Janeiro: Forense, 2011, p. 204.
} 
existência de outras fontes do direito fora da própria Constituição ${ }^{46}$, o que possibilita a incorporação ao direito brasileiro de normas constitucionais não expressas no texto constitucional. A esse respeito Estefânia Maria de Queiroz Barboza ensina:

No Brasil, é possível identificar a existência de uma Constituição invisível especialmente no que diz respeito aos princípios implícitos, aos princípios gerais do direito e aos direitos humanos e fundamentais, tendo em vista o que estabelece o art. $5^{\circ}, \S 2^{\circ}$, da Carta Constitucio$\mathrm{nal}^{47}$.

O próprio Supremo Tribunal Federal já reconheceu a existência de uma Constituição brasileira invisível, por ocasião do julgamento da Intervenção Federal tombada sob número 2.915, ao decidir que o princípio da proporcionalidade, embora não expresso na Constituição Federal, decorreria do princípio do devido processo legal material ${ }^{48}$.

As normas da Convenção Quadro de Controle do Tabaco integram, ainda que estejam fora do texto constitucional escrito, a Constituição material e invisível da República Federativa do Brasil. Assim, os direitos consagrados na aludida convenção compõem o catálogo dos direitos constitucionalmente protegidos e devem ser tutelados no âmbito interno da jurisdição brasileira, sob pena de responsabilidade internacional.

O consumo do tabaco é, na lição de Dalmo de Abreu Dallari, um dos principais males que afeta o direito fundamental à saúde, inclusive de terceiros que são expostos à fumaça exalada pelo fumante, de modo que há a necessidade da adoção de medidas de controle do tabaco, inclusive de sua publicidade ${ }^{49}$.

A Convenção Quadro e a Constituição Federal de 1988 reconhecem os malefícios do fumo à saúde humana, tanto que preveem restrições à publicidade do tabaco. A Carta Constitucional determina que, conforme ressaltado alhures, a propaganda comercial de tabaco estará sujeita a restrições legais e, por sua vez, o artigo 13.2 da Convenção Quadro estabelece que os Estados deverão proceder à

\footnotetext{
$\overline{46}$ BARBOZA, Estefânia Maria de Queiroz. Precedentes judiciais e segurança jurídica: fundamentos e possibilidades para a jurisdição constitucional brasileira. São Paulo: Saraiva, 2014, p. 178.

${ }^{47}$ Ibidem, 2014, p. 179.

${ }^{48}$ BRASIL. Supremo Tribunal Federal. IF n. 2.915/SP. Requerente: Nair de Andrade e outros. Requerido: Estado de São Paulo. Relator Ministro Marco Aurélio. 03 de fevereiro de 2003. Disponível em: < http://www. stf.jus.br/portal/jurisprudencia/listarJurisprudencia.asp?s1 = \%28IF\%24\%2ESCLA\%2E +E + 2915\%2ENUME $\% 2 \mathrm{E} \% 29+\mathrm{OU}+\% 28 \mathrm{IF} \% 2 \mathrm{EACMS} \% 2 \mathrm{E}+\mathrm{ADJ} 2+2915 \% 2 \mathrm{EACMS} \% 2 \mathrm{E} \% 29 \&$ base = baseAcordaos\&url =http:// tinyurl.com/crx3e2t > . Acesso em: 26 dez. 2015.

${ }^{49}$ DALLARI, op. cit., 2015, p. 38.
} 
proibição total de toda forma de publicidade, promoção e patrocínio do tabaco.

$\mathrm{O}$ art. $220, \S 4^{\circ}$, da Constituição Federal de 1988 permite a restrição da publicidade de tabaco, mas não a sua proibição $0^{50}$, tese essa inclusive sustentada pela Confederação Nacional da Indústria na Ação Direta de Inconstitucionalidade n. 3.311, razão pela qual o art. $3^{\circ}$ da Lei Federal n. ${ }^{\circ} 9.294$, de 15 de julho de 1996, com a redação dada pela Lei n. ${ }^{\circ} 12.546$, de 14 de dezembro de 2011, seria inconstitucional.

Entretanto, o pensamento jurídico de que a Constituição Federal não permite a proibição da publicidade do tabaco não encontra eco na própria ordem constitucional brasileira.

Com efeito, ainda que se admitisse que o artigo 220, $\S 4^{\circ}$ da Constituição da República não veda a publicidade do tabaco, verdade é que a Convenção Quadro para o Controle do Tabaco a proíbe e, nesse caso, ter-se-ia um caso claro de antinomia entre o direito constitucional interno e o direito internacional dos direitos humanos, cuja solução se dá a partir da promoção do diálogo entre o direito constitucional brasileiro e o direito internacional dos direitos humanos fundado na proteção do ser humano, acolhendo-se o diploma normativo e a hermenêutica mais favorável à dignidade humana e, portanto, a mais protetiva e favorável ao indivíduo ${ }^{51}$.

Nesse caso, deve prevalecer a Convenção Quadro para o Controle do Tabaco e, por conseguinte, a proibição da publicidade, eis que tal vedação tem por finalidade precípua a salvaguarda da vida com dignidade e a saúde humana ${ }^{52}$ e é mais benéfica e protetiva ao ser humano do que a mera restrição parcial, uma vez que "as proibições parciais e os acordos voluntários tiveram pouco ou nenhum efeito sobre os níveis de consumo de tabaco" ${ }^{53}$.

Poder-se-ia também aduzir que a proibição da publicidade do tabaco é mais restritiva aos direitos humanos porque afeta negativamente a liberdade de expressão. Contudo, o regime jurídico da publicidade comercial deve ser compreendido e aplicado a partir da caracterização da publicidade como princípio da ordem econômica e não como corolário lógico do direito fundamental à liberdade de

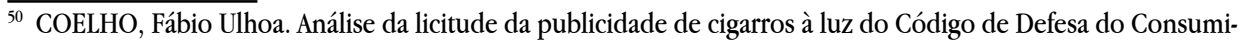
dor. In: LOPEZ, Tereza Ancona (Coord.). Estudos e pareceres sobre livre arbítrio, responsabilidade e produto de risco inerente: o paradigma do tabaco: aspectos civis e processuais. Rio de Janeiro: Renovar, p. 155-181, 2009, p. 175.

${ }^{51}$ PIOVESAN, Flávia. Sistema interamericano de direitos humanos: impacto transformador, diálogos jurisdicionais e os desafios da reforma. Revista de Estudos Constitucionais, Hermenêutica e Teoria do Direito, vol. 06, n. 02, p. 142-154, jul./set. 2014, p. 150.

52 PASQUALOTTO, op. cit., 2014, p. 177.

53 CABRERA; GUILLEN; CARBALLO, op. cit., 2015, p. 262.
} 
expressão $0^{54}$.

A publicidade comercial tem propósito eminentemente econômico, uma vez que se trata de um meio de divulgação de bens e serviços com a finalidade de incentivar o seu consumo. É através das mensagens mercadológicas que o fornecedor leva ao conhecimento dos consumidores em geral a existência de seus produtos a serem eventualmente adquiridos, aumentando, assim, os seus lucros ${ }^{55}$. Tal publicidade está diretamente vinculada à livre iniciativa e não à liberdade de expressão porque seu escopo é persuadir o consumidor a comprar e esta finalidade "determina que a sede do seu tratamento jurídico é preferencialmente a livre iniciativa" $"$.

$\mathrm{O}$ vínculo da publicidade comercial com o princípio da livre iniciativa a inclui na chamada Constituição econômica e não no rol dos direitos fundamentais, o que permite maior restrição à atividade publicitária ${ }^{57}$.

Outrossim, ainda que a proibição da publicidade do tabaco imposta pela Convenção Quadro para o Controle do Tabaco restringisse a liberdade de expressão ainda assim tal instrumento normativo internacional seria, segundo um juízo de proporcionalidade, mais protetivo e favorável ao ser humano.

O princípio da proporcionalidade é instrumento necessário para aferir a legitimidade dos atos estatais que restringem direitos humanos e direitos fundamentais ${ }^{58}$. O princípio da proporcionalidade impõe o respeito concomitante de três requisitos, quais sejam: a) adequação; b) necessidade; e c) proporcionalidade em sentido estrito.

A adequação impõe que as medidas restritivas a direitos (os meios) sejam aptas a proteger os direitos humanos e os direitos fundamentais de terceiros (os fins), ou seja, o meio deve promover o fim almejado ${ }^{59}$. No caso, a proibição da publicidade do tabaco é um meio adequado a atingir sua finalidade porque é apta e eficaz para impedir o início, bem como a redução do consumo de produtos derivados do fumo e é, consequentemente, benéfico para a saúde pública ${ }^{60}$.

Por sua vez, a necessidade consiste na escolha, dentre os meios disponíveis

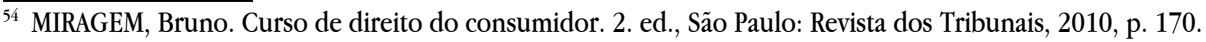

${ }_{55}$ DIAS, Lucia Ancona Lopez de Magalhães. Publicidade e direito. São Paulo: Revista dos Tribunais, 2010, p. 21.

56 PASQUALOTTO, Adalberto. Prefácio. In: PAQUALOTTO, Adalberto (Org.). Publicidade de tabaco: frente e verso da liberdade de expressão comercial. São Paulo: Atlas, 2015, p. xii.

${ }^{57}$ Ibidem, 2015, p. xiii.

${ }^{58}$ PIEROTH, Bodo; SCHLINK, Bernhard. Direitos fundamentais. São Paulo: Saraiva, 2012, p. 138.

59 ÁVILA, Humberto. Teoria dos princípios: da definição à aplicação dos princípios jurídicos. 14. ed., São Paulo: Malheiros, 2013, p. 188.

${ }^{60}$ CABRERA; GUILLEN; CARBALLO, op. cit., 2015, p. 261.
} 
e igualmente adequados para promover o fim, daquele menos oneroso e lesivo aos direitos humanos afetados ${ }^{61}$. A proibição da publicidade do tabaco é necessária porque é a única resposta capaz de promover a efetiva proteção da saúde contra a epidemia do tabagismo e contra os esforços da indústria do tabaco destinados a aumentar os seus lucros com o incremento das vendas de seus produtos ${ }^{62}$.

Sobre o requisito da necessidade, Adalberto Pasqualotto ensina que:

Diante das evidências médicas, não há dúvida sobre a necessidade de combater os males do tabagismo. Também ninguém ignora o poder de sedução da publicidade, especialmente, neste caso, sobre as camadas mais jovens da população, que são o alvo principal da indústria tabagista. Não é possível levar a sério o argumento de que a publicidade do tabaco visa, tão somente, a influenciar quem já é fumante a mudar de marca, sem o objetivo de expandir o universo de fumantes. A restrição à publicidade do tabaco não só é necessária, como está expressamente autorizada pelo constituinte. A alternativa à restrição total seria a restrição parcial, promovendo-se, em paralelo, campanhas de esclarecimento da população. Essa política, todavia, não seria tão eficiente quanto a restrição total, uma vez que as campanhas que promovem as marcas de cigarros são muito mais eficientes do que as campanhas antitabaco. As alternativas de política tributária, onerando o preço dos produtos do tabaco, sugerida por alguns autores, como Jónatas Machado, já são praticadas no Brasil e mostraram-se historicamente insuficientes ${ }^{63}$.

Finalmente, a proporcionalidade em sentido estrito exige que as vantagens da interferência na esfera dos direitos dos cidadãos superem os ônus decorrentes da limitação a direitos humanos, ou seja, o benefício alcançado com a adoção da medida restritiva não deve sacrificar direitos humanos mais importantes axiologicamente do que os direitos que a medida pretendeu preservar ${ }^{64}$.

A proibição da publicidade do tabaco atende ao terceiro e último requisito porque sacrifica a liberdade comercial e a liberdade de expressão da indústria do tabaco com o objetivo de promover e a proteger bens fundamentais mais importantes, quais sejam, o direito fundamental à vida digna e saudável e o direito fundamental à saúde. Enfim, os bens tutelados pela vedação à propaganda do cigarro são mais caros à sociedade em geral do que interesses corporativos e econômicos da indústria

\footnotetext{
${ }_{61}$ ÁVILA, op. cit., 2013, p. 193.

${ }^{62}$ CABRERA; GUILLEN; CARBALLO, op. cit., 2015, p. 262.

63 PASQUALOTTO, Adalberto. Publicidade de tabaco e liberdade de expressão. Revista de Direito do Consumidor, vol. 82, p. 11-59, abr./jun/ 2012, p. 28.

${ }^{64}$ MARMELSTEIN, George. Curso de direito fundamentais. 3. ed., São Paulo: Atlas, 2011, p. 419.
} 
tabacaleira.

Destarte, a partir do diálogo entre as ordens jurídicas nacional e internacional, deve prevalecer a Convenção Quadro e, por conseguinte, a proibição da publicidade do tabaco porque é, como já afirmado, mais benéfica e protetiva ao ser humano.

Por fim, registre-se que se o texto constitucional escrito e formal da Constituição Federal não permite, segundo alguns juristas, a proibição da publicidade do tabaco, verdade é que as normas da Convenção Quadro de Controle do Tabaco integram, por serem mais favoráveis à dignidade humana, a Constituição material e invisível da República Federativa do Brasil.

Portanto, a publicidade do tabaco está vedada pelo próprio ordenamento constitucional brasileiro e, por consequência, não há qualquer vício de inconstitucionalidade no art. $3^{\circ}$ da Lei Federal n. 9.294, de 15 de julho de 1996, devendo a Ação Direta de Inconstitucionalidade tombada sob número 3.311 ser julgada, nesse ponto ora analisado, improcedente.

\section{CONSIDERAÇÕES FINAIS}

O objetivo central deste artigo científico foi demonstrar que a publicidade do tabaco está proibida pelo ordenamento constitucional brasileiro e, por consequência, não há qualquer vício de inconstitucionalidade na vedação legal imposta pelo art. $3^{\circ}$ da Lei Federal n. 9.294, de 15 de julho de 1996.

Partiu-se da premissa de que a defesa do consumidor é direito fundamental da pessoa humana e princípio constitucional expresso no art. 170, inciso V, da Constituição da República, de aplicabilidade direta e imediata, que impõe ao Estado a implementação de medidas fáticas e jurídicas de caráter interventivo voltadas à proteção do consumidor e limites à livre iniciativa e à autonomia da vontade.

A indústria do tabaco se utiliza de táticas de publicidade com o propósito de estimular psicologicamente o consumidor a adquirir novos produtos, de angariar novos consumidores, de fragilizar as campanhas de saúde pública e de incentivar ex-fumantes a voltar ao vício. É mister, nesse cenário, proteger o consumidor da publicidade de tabaco porque se trata de produto altamente nocivo à vida e à saúde humana.

A Constituição formal da República Federativa do Brasil previu, em seu art. $220, \S 4^{\circ}$, a possibilidade de restrições, por meio de lei federal, a propaganda 
comercial de produtos nocivos ao ser humano, inclusive o tabaco.

Nos termos disciplinados pela Constituição formal, a Lei Federal n. ${ }^{\circ}$ 9.294, de 15 de julho de 1996, aduz, em seu art. $3^{\circ}$, com a redação dada pela Lei $n$. ${ }^{\circ}$ 12.546, de 14 de dezembro de 2011, que "é vedada, em todo o território nacional, a propaganda comercial de cigarros, cigarrilhas, charutos, cachimbos ou qualquer outro produto fumígeno, derivado ou não do tabaco".

A Confederação Nacional da Indústria propôs, no entanto, ação direta de inconstitucionalidade, perante o Supremo Tribunal Federal, visando, dentre outros pedidos, a declaração de inconstitucionalidade da proibição legal à publicidade do tabaco, por entender, em suma, que tal medida restritiva viola o princípio da proporcionalidade.

Ocorre que, a solução da controvérsia constitucional posta na Ação Direta de Inconstitucionalidade tombada sob número 3.311 passa necessariamente pelo diálogo entre a ordem jurídica brasileira e o ordenamento jurídico internacional de proteção dos direitos humanos.

$\mathrm{O}$ art. 13.2 da Convenção Quadro de Controle do Tabaco recomenda a proibição da publicidade e promoção de produtos do tabaco. O referido instrumento normativo tem a natureza jurídica especial de tratado internacional de direitos humanos e seus preceitos são vinculativos e obrigatórios por parte dos Estados signatários.

$\mathrm{Na}$ qualidade de tratado internacional de direitos humanos, foi incorporada ao direito nacional como norma constitucional. As normas da Convenção Quadro de Controle do Tabaco integram, ainda que estejam fora do texto constitucional formal e escrito, a Constituição material e invisível da República Federativa do Brasil.

Assim, os direitos consagrados na aludida convenção compõem o catálogo dos direitos constitucionalmente protegidos e devem ser tutelados no âmbito interno da jurisdição brasileira, sob pena de responsabilidade internacional.

Ademais, ainda que se admitisse que o artigo 220, $\S 4^{\circ}$ da Constituição da República não veda a publicidade do tabaco, verdade é a Convenção Quadro para o Controle do Tabaco conclama os Estados partes a proibir a publicidade do tabaco e, assim, ter-se-ia um caso claro de antinomia entre o direito constitucional interno e o direito internacional dos direitos humanos, cuja solução se dá a partir da promoção do diálogo entre o direito constitucional brasileiro e o direito internacional fundado na proteção do ser humano, acolhendo-se o diploma normativo e a hermenêutica mais favorável à dignidade humana e, portanto, a mais protetiva e favorável à pessoa. 
Nesse caso, deve prevalecer a Convenção Quadro e, por conseguinte, a possibilidade de proibição da publicidade do tabaco, eis que tal vedação tem por finalidade precípua a salvaguarda da vida com dignidade e a saúde humana e é mais benéfica e protetiva ao ser humano do que a mera restrição parcial.

Dessa forma, não há qualquer vício de inconstitucionalidade no art. $3^{\circ}$ da Lei Federal n. 9.294, de 15 de julho de 1996, devendo a Ação Direta de Inconstitucionalidade tombada sob número 3.311 ser julgada, nesse ponto, improcedente porque a publicidade do tabaco está vedada pelo próprio ordenamento constitucional brasileiro. Vale dizer: pela Constituição material e invisível do Brasil.

\section{REFERÊNCIAS}

ALCALÁ, Humberto Nogueira. El diálogo interjurisdiccional y control de convencionalidad entre tribunales nacionales y Corte Interamericana de Derechos Humanos en Chile. In: SARLET, Ingo Wolfgang; GOMES, Eduardo Biacchi; STRAPAZZON, Carlos Luiz (Org.). Direitos humanos e fundamentais na América do Sul. Porto Alegre: Livraria do Advogado, 2015.

ALEXY, Robert. Conceito e validade do direito. São Paulo: WMF Martins Fontes, 2009

ALEXY, Robert. Teoria dos direitos fundamentais. Tradução de Virgílio Afonso da Silva. São Paulo: Malheiros, 2008.

ÁVILA, Humberto. Teoria dos princípios: da definição à aplicação dos princípios jurídicos. 14. ed., São Paulo: Malheiros, 2013.

BARBOZA, Estefânia Maria de Queiroz. Precedentes judiciais e segurança jurídica: fundamentos e possibilidades para a jurisdição constitucional brasileira. São Paulo: Saraiva, 2014.

BARROSO, Luís Roberto. Curso de direito constitucional contemporâneo: os conceitos fundamentais e a construção do novo modelo. 4. ed.. São Paulo: Saraiva, 2013.

BAUMAN, Zygmunt. Vida para o consumo: a transformação das pessoas em 
mercadoria. Rio de Janeiro: Zahar, 2008.

BECK, Ulrich. Ecological Politics in an Age of Risk. Londres: Polity Publications, 1995.

BOUDRILLARD, Jean. A sociedade de consumo. 3.ed. Lisboa: Edições 70, 2011.

BRASIL. Supremo Tribunal Federal. IF n. 2.915/SP. Requerente: Nair de Andrade e outros. Requerido: Estado de São Paulo. Relator Ministro Marco Aurélio. 03 de fevereiro de 2003. Disponível em: < http://www.stf.jus.br/portal/jurisprudencia/listarJurisprudencia.asp?s1 = \%28IF\%24\%2ESCLA\%2E +E+2915\%2ENUME $\% 2 \mathrm{E} \% 29+\mathrm{OU}$ $+\% 28 \mathrm{IF} \% 2 \mathrm{EACMS} \% 2 \mathrm{E}+\mathrm{ADJ} 2+2915 \% 2 \mathrm{EACMS} \% 2 \mathrm{E} \% 29$ \&base $=$ baseAcordaos\&url=http://tinyurl.com/cvx3e2t $>$. Acesso em: 11 jan. 2016.

CABRERA, Oscar; GUILLEN, Paula Ávila; CARBALLO, Juan. Viabilidade jurídica de una proibição completa da publicidade de tabaco: o caso perante a Corte Constitucional da Colômbia. In: PASQUALOTTO, Adalberto (Org.). Publicidade de tabaco: frente e verso da liberdade de expressão comercial. São Paulo: Atlas, p. 253-275, 2015.

CANOTILHO, José Joaquim Gomes. Direito constitucional e teoria da Constituição. 7. ed. Coimbra: Almedina, 2011.

COELHO, Fábio Ulhoa. Análise da licitude da publicidade de cigarros à luz do Código de Defesa do Consumidor. In: LOPEZ, Tereza Ancona (Coord.). Estudos e pareceres sobre livre arbítrio, responsabilidade e produto de risco inerente: o paradigma do tabaco: aspectos civis e processuais. Rio de Janeiro: Renovar, p. 155$181,2009$.

DALLARI, Dalmo de Abreu. Controle do uso do tabaco: constitucionalidade do controle da distribuição e da publicidade. In: PASQUALOTTO, Aldaberto (Org.). Publicidade de tabaco: frente e verso da liberdade de expressão comercial. São Paulo, Atlas, p. 38-45, 2015.

DIAS, Lucia Ancona Lopez de Magalhães. Publicidade e direito. São Paulo: Revista dos Tribunais, 2010.

DIAS, Lucia Ancona Lopez de Magalhães. Publicidade e hipervulneráveis: limitar, 
proibir ou regular? Revista de Direito do Consumidor, vol. 99, p. 285-305, mai./ jun. 2015.

DONNELLY, Jack. Universal human rights in theory and practice. 3. ed., New York: Cornell University Press, 2013.

EFING, Antônio Carlos. Fundamentos do direito das relações de consumo. 3. ed.. Curitiba: Juruá, 2011.

FAJARDO, Elias. Consumo consciente, comércio justo: conhecimento e cidadania como fatores econômicos. Rio de Janeiro: Senac Nacional, 2010.

GRAU, Eros Roberto. A ordem econômica na Constituição de 1988. 15. Ed.. São Paulo: Malheiros, 2012.

MARCUSE, Herbert. O homem unidimensional: estudos da ideologia da sociedade industrial avançada. São Paulo: EDIPRO, 2015.

MARMELSTEIN, George. Curso de direito fundamentais. 3. ed., São Paulo: Atlas, 2011.

MIRAGEM, Bruno. Curso de direito do consumidor. 2. ed., São Paulo: Revista dos Tribunais, 2010.

MIRAGEM, Bruno. O direito do consumidor como direito fundamental: consequências jurídicas de um conceito. Revista de Direito do Consumidor. Vol. 43, p. 111132, jul./set. 2002.

MIRAGEM, Bruno; MARQUES, Cláudia Lima. A constitucionalidade das restrições à publicidade do tabaco por lei federal: diálogo e adequação do princípio da livre iniciativa econômica à defesa do consumidor e da saúde pública. In: PASQUALOTTO, Adalberto (org.). Publicidade de tabaco: frente e verso da liberdade de expressão. São Paulo: Atlas, p. 03-37, 2015.

MIRANDA, Jorge. Teoria do Estado e da Constituição. Rio de Janeiro: Forense, 2011.

MÖLLER, Max. Teoria geral do neoconstitucionalismo: bases teóricas do constitu- 
cionalismo contemporâneo. Porto Alegre: Livraria do Advogado, 2011.

ORGANIZAÇÃO MUNDIAL DA SAÚDE. Who report on the global tabacco epidemic: raising taxes on tabacco, 2015. Disponível em: < http://apps.who.int/iris/bitstre am/10665/178574/1/9789240694606_eng.pdf?ua=1\&ua=1>. Acesso em: 31 maio 2016.

PASQUALOTTO, Adalberto. A Convenção Quadro para o controle do tabaco como reforço da constitucionalidade da proibição da publicidade do tabaco. Revista de Direito do Consumidor, vol. 91, p. 169-208, jan/fev. 2014.

PASQUALOTTO, Adalberto. Direito e publicidade em ritmo de descompasso. Revista de Direito do Consumidor, vol. 100, p. 501-527, jul./ago. 2015.

PASQUALOTTO, Adalberto. Fundamentalidade e efetividade da defesa do consumidor. Direitos Fundamentais \& Justiça, vol. 9, p. 66-100, out./dez 2009.

PASQUALOTTO, Adalberto. Prefácio. In: PAQUALOTTO, Adalberto (Org.). Publicidade de tabaco: frente e verso da liberdade de expressão comercial. São Paulo: Atlas, 2015.

PASQUALOTTO, Adalberto. Publicidade de tabaco e liberdade de expressão. Revista de Direito do Consumidor, vol. 82, p. 11-59, abr./jun/ 2012.

PIEROTH, Bodo; SCHLINK, Bernhard. Direitos fundamentais. São Paulo: Saraiva, 2012.

PIOVESAN, Flávia. Direitos humanos e o direito constitucional internacional. 14. ed., São Paulo: Saraiva, 2013.

PIOVESAN, Flávia. Sistema interamericano de direitos humanos: impacto transformador, diálogos jurisdicionais e os desafios da reforma. Revista de Estudos Constitucionais, Hermenêutica e Teoria do Direito, vol. 06, n. 02, p. 142-154, jul./set. 2014.

PORTILHO, Fátima. Sustentabilidade ambiental, consumo e cidadania. 2.ed. São Paulo: Cortez, 2010.

SARLET, Ingo Wolfgang. A eficácia dos direitos fundamentais: uma teoria geral 
dos direitos fundamentais na perspectiva constitucional. 12. ed.. Porto Alegre: Livraria do Advogado, 2015.

SARLET, Ingo Wolfgang. Dignidade da pessoa humana e direitos fundamentais na Constituição Federal de 1988. 9. ed.. Porto Alegre: Livraria do Advogado, 2012. SARLET, Ingo Wolfgang; MARINONI, Luiz Guilherme; MITIDIERO, Daniel. Curso de direito constitucional. 4. ed., São Paulo: Saraiva, 2015.

Recebido em: 12 de fevereiro de 2016 Aceito em: 29 de junbo de 2016 